\title{
Research on Human Resource Incentive Measures in Public Institutions
}

\author{
Li Haiping \\ Changqing District, Yellow River Bureau, Jinan Yellow River Bureau, Jinan, China
}

\section{Email address:}

35195341@qq.com

\section{To cite this article:}

Li Haiping. Research on Human Resource Incentive Measures in Public Institutions. Science Innovation. Vol. 9, No. 4, 2021 , pp. 167-169. doi: 10.11648/j.si.20210904.19

Received: May 20, 2021; Accepted: June 25, 2021; Published: July 9, 2021

\begin{abstract}
This paper takes the human resource incentive measures of public institutions as the analysis object, first introduces the related concepts, then analyzes the important significance value of human resource incentive of public institutions, then elaborated the question which the institution Human Resources Incentive measure exists, finally elaborated the institution human resources positive measure ponder. With the gradual emergence of the form of global economic integration, the degree of international competition is becoming increasingly day by day. The increasing market competition brings huge business opportunities as well as challenges to the domestic market, we need to face up to the advantages and disadvantages of economic globalization and constantly strengthen internal management. In order to improve the incentive quality of human resources in public institutions, public institutions need to change their thinking and set up people-oriented incentive thoughts, and at the same time, they also need to explore diversified incentive means, design salary rationally and improve feedback mechanism, in order to improve the incentive quality of public institutions, to stimulate the enthusiasm of staff work. Effective material incentives can often attract outstanding talent, outstanding talent in the incentive measures under the more easy to play their potential, so that public institutions to retain and attract high-speed talent, in order to improve the quality of work in public institutions.
\end{abstract}

Keywords: Public Institutions, Incentive Mechanism, Motivational Thinking

\section{事业单位人力资源激励措施探究}

\section{李海平}

长清黄河河务局, 济南黄河河务局, 济南, 中国

\section{邮箱}

35195341@qq.com

摘要：本文以事业单位人力资源激励措施为分析对象, 首先介绍了相关的概念, 接着分析了事业单位人力资源激励的重 要意义价值, 再接着阐述了事业单位人力资源激励措施存在的问题, 最后论述了事业单位人力资源积极措施的思考。伴 随全球经济一体化形式的逐渐彰显，国际间的竞争激励化程度日益白日化，不断增强的市场竞争给国内带来挑战的同时 带来巨大的商机, 因此, 需要正视经济全球化的利弊, 不断强化内部管理。为提升事业单位人力资源激励的质量, 事业 单位需要转变思想, 树立以人为本的激励思想, 同时还需要探索多元化激励手段, 合理设计薪酬, 完善反馈机制, 以此 提高事业单位激励质量, 激发员工工作的积极性。有效的物质激励常常可以吸引优秀的人才, 优秀的人才在激励措施的 激励之下更容易发挥自身的潜能，使事业单位留住和吸引高速的人才，以便提升事业单位工作的质量。

关键词：事业单位，激励机制，激励思想 


\section{1. 引言}

在经济全球化的大背景下, 为提升事业单位员工工 作的积极性, 许多事业单位纷纷加强了人力资源激励, 希望通过高质量的激励措施提高工作人员的工作积极 性, 以此提升工作质量。在传统的经济模式之中, 事业 单位并没有坚持以人为本的激励思想, 在激励的过程之 中并没有重视人的价值, 因此导致系措施不完善, 难以 真正提高员工工作积极性。为提升事业单位的激励质量, 事业单位可以采用多元化的激励措施, 除了加强物质激 励之外还可以积极探索精神激励等不同激励措施, 提高 员工工作的积极性。有效的物质激励常常可以吸引优秀 的人才，优秀的人才在激励措施的激励之下更容易发挥 自身的潜能, 使事业单位留住和吸引高速的人才, 以便 提升事业单位工作的质量。

\section{2. 相关概念的介绍}

\section{1. 事业单位}

事业单位是对我国非政府机关以及社会团体等从事 公共服务组织的称呼, 其主要是以服务社会作为目的, 是 由国家出资并创设的服务机构, 分布在我国教育、文化、 卫生、科技等各个不同的行业[1]。

\section{2. 人力资源}

人力资源主要是指一个单位内部员工资源的总和, 这 种资源包括员工的脑力劳动, 同时也包含有员工的体力劳 动。与其他的资源相比, 人力资源具有投入少而回报大等 一系列特点, 同时人力资源也是事业单位各项资源中最为 宝贵的一项资源 $[2,3]$ 。

\section{3. 事业单位人力资源激励的重要意义}

事业单位是国家政府所设置的公益性机构, 因此事业 单位具有服务性质的特点, 事业单位加强人力资源激励具 有以下几方面的重要意义。

第一, 可以优化资源配置。事业单位的有效激励措施 可以确保人才发挥自身的潜能, 同时也可以激发员工工作 的积极性, 通过合理的划分使员工寻找到属于自身的工作 岗位, 因此实现资源的合理配置[4]。

第二, 留住和吸引高素质人才。有效的物质激励常常 可以吸引优秀的人才, 优秀的人才在激励措施的激励之下 更容易发挥自身的潜能, 使事业单位留住和吸引高速的人 才，以便提升事业单位工作的质量。

第三, 充分调动人才的工作积极性。由于事业单位具 有较强的稳定性, 要想充分调动人员的积极性还必须采取 强有力的激励措施, 强有力的激励措施可以激发员工的荣 誉感, 同时也可以激发员工的成就感, 可以有效调动员工 工作的积极性, 以此提高工作效率。

\section{4. 事业单位人力资源激励措施存在的问题}

目前, 我国许多事业单位非常注重激励机制的建设, 在激励机制方面也做出了许多有益的探索, 但是我国事业 单位在激励机制方面存在一些问题主要体现在以下几方 面。

第一，管理思想陈旧，激励思想落后。由于事业单位 是由国家所创设, 事业单位的工作带有公益性质, 因此事 业单位的稳定性非常突出。在人力资源的激励措施之中, 各项激励措施依旧遵循的是传统的管理思想, 缺乏先进的 指导理念, 并没有注重激励措施与员工的需求结合, 许多 激励措施只是停留在表面, 并不能够真正起到激励的作 用, 也难以真正提升事业单位员工的工作潜能 [5]。

第二, 激励方式单一, 过于注重物质奖励。在各种激 励措施之中, 物质激励是激励措施的一种模式, 除了物质 激励之外还包含其他多种不同的激励方式, 例如精神激励 等。但是, 事业单位在激励时更多注重的是物质激励, 致 使事业单位的激励方式单一, 单纯的物质激励难以真正调 动员工工作的激情, 也难以真正提升员工工作的质量。单 纯的物质激励只能在短时间内激发员工工作的潜力, 无法 维持长期的激励效果, 如果缺乏其他的激励措施, 员工的 激励效果会大打折扣, 同时也会影响到事业单位激励机制 的质量。

第三, 薪酬结构并不科学, 绩效考核制度不完善。目 前, 事业单位的薪酬结构设计并不科学, 事业单位的绩效 考核制度也不够完善, 事业单位并没有根据不同岗位设置 不同的考核内容，同时也没有结合不同的岗位设计不同的 薪酬结构, 更多的只是依赖员工的职称等静态指标进行考 核, 并不注重员工工作质量等实际工作效果的绩效考核 [6, 7]。正是由于事业单位薪酬结构过于平衡, 缺乏激励性的 薪酬模式, 因此事业单位的薪酬难以激励, 员工工作也难 以调动员工工作的积极性 [8]。

第四, 缺乏有效的沟通反馈机制。目前, 事业单位内 部行政管理色彩非常浓厚, 事业单位内部的等级划分非常 严格, 这种严格的等级划分无法实现高质量的沟通, 也无 法就极力的反馈意见传递至管理层。在事业单位内部, 员 工与管理层之间的互动交流非常少, 管理层无法掌握员工 的真实思想动态, 员工也无法将自身的思想传递给管理 层, 致使管理层与员工之间出现了思想隔阂, 最终会影响 到激励机制的效果。

\section{5. 事业单位人力资源激励措施的思考}

为提升激励质量, 事业单位需要不断完善人力资源激 励措施, 同时需要创新新的激励方式和方法, 以此提高事 业单位激励的质量。

第一, 树立以人为本的激励思想。在传统的经济模式 之中, 事业单位并没有坚持以人为本的激励思想, 在激励 的过程之中并没有重视人的价值, 因此导致系措施不完 善, 难以真正提高员工工作积极性。为提高事业单位人力 资源激励的质量, 事业单位需要不断完善激励思想, 树立 
以人为本的激励理念, 同时还需要根据不同人的工作能力 实施差异化的激励政策 $[9,10]$ 。比如, 对于工作热情非常 高的员工, 事业单位可以赋予其更多的职责，为他们的发 展提供更大的舞台, 以最大程度满足他们的需求, 提升激 励质量[11]。对一般的员工事业单位可加强能力培训, 同 时可以激发他们的工作热情, 以此提高员工工作的积极 性。对于缺乏工作积极性的员工，事业单位可以通过考核 倒逼其认真工作, 如果员工工作态度依旧散乱, 事业单位 可以采取换岗或者是放弃的策略。因此事业单位可以对不 同的员工采用不同的措施, 以此激发员工的竞争意识, 同 时也激发员工工作的潜能, 提升员工工作的积极性 [12]。

第二, 采用多元化的激励手段。为提升事业单位的激 励质量, 事业单位可以采用多元化的激励措施, 除了加强 物质激励之外还可以积极探索精神激励等不同激励措施, 提高员工工作的积极性。为此, 事业单位可以在内部开展 优秀员工评比工作, 通过优秀员工评比使不同的员工获得 晋升的机会, 同时还可以关心员工的个人生活, 为员工的 工作创造良好的工作环境, 以此增强员工的凝聚力, 同时 也增强员工对事业单位的归属感，使员工拥有主人翁的思 想, 使员工可以积极主动的投入到工作之中，以此提升工 作的质量 $[13,14]$ 。

第三，合理设计薪酬，完善考核机制。薪酬激励是最 为有效的激励模式, 当前事业单位的薪酬激励结构并不科 学也不灵活, 事业单位的薪酬设计更加重视平衡性, 忽视 了对员工的激励和考核, 无差别的薪酬难以使员工提升工 作积极性。为此事业单位需要合理设计薪酬结构, 考虑到 工作能力各级等方面的差异, 为不同的工作人员设置不同 的考核标准和内容, 以此建立起完善的考核机制, 以提高 员工工作的积极性。

第四, 创建完善的反馈机制。为提高事业单位人力资 源激励质量, 事业单位需要创造良好的反馈机制, 通过良 好的反馈机制提升事业单位人力资源激励的质量。为此, 事业单位需要加强公司高层与基层员工之间的沟通, 创建 沟通协调机制, 使公司高层了解基层员工的想法, 使基层 员工可以将思想传递给公司高层, 以便可以完善公司人力 资源激励机制, 提升激励质量, 加强激励的针对性和有效 性。

\section{6. 结语}

综上所述, 为提升事业单位人力资源激励的质量, 事 业单位需要转变思想, 树立以人为本的激励思想, 同时还 需要探索多元化激励手段, 合理设计薪酬, 完善反馈机制, 以此提高事业单位激励质量, 激发员工工作的积极性。强 有力的激励措施可以激发员工的荣誉感, 同时也可以激发 员工的成就感, 可以有效调动员工工作的积极性, 以此提
高工作效率 [15]。有效的物质激励常常可以吸引优秀的人 才, 优秀的人才在激励措施的激励之下更容易发挥自身的 潜能, 使事业单位留住和吸引高速的人才, 以便提升事业 单位工作的质量。事业单位需要不断完善人力资源激励措 施, 同时需要创新新的激励方式和方法, 以此提高事业单 位激励的质量。

\section{参考文献}

[1] 李艳艳. 事业单位人力资源管理激励措施探讨 [J]. 中国市 场, 2020(21).

[2] 杨水林. 人力资源柔性管理模式研究 [J]. 人力资源管理, 2016.

[3] 毕鸿程. 关于人力资源管理研究分析 [J]. 消费导刊, 2015.

[4] 王颖曼. 事业单位人力资源管理中的激励机制探讨 [J]. 现 代营销(信息版), 2020(04):197-198.

[5] 代德荣. 关于事业单位人力资源管理过程中的激励机制探 讨[J]. 财经界, 2020, 000(012):239-240.

[6] 张瑞婷. 事业单位人力资源管理中的激励机制探讨 [J]. 环 渤海经济瞭望, 2019, No.299(08):97-98.

[7] 刘秀华. 我国事业单位人力资源激励机制存在的问题及对 策探究[J]. 全国流通经济, 2019.

[8] 徐蔚. 浅谈事业单位绩效工资发放和激励机制运行策略 [J]. 纳税, 2019.

[9] 王新. H公司员工激励问题研究[J]. 黑龙江大学硕士论文, 2020.

[10] 韦合炼. 浅析机关绩效考核存在的不足和对策[J]. 中国高 新技术企业, 2016.

[11] 杜向凯. 事业单位人力资源管理中的激励机制研究 [J]. 中 国战略新兴产业(理论版), 2019, 000(005):1-2.

[12] 许瀕. 敢于管理与善于管理的理性思考 [J]. 兰台世界, 2008.

[13] 陈威. 浅谈如何提高事业单位政工队伍素质[J]. 大同日报, 2020.

[14] 周鹏. 浅谈事业单位职工思想政治工作的创新 [J]. 商情, 2014.

[15] 张哲. 从人力资源危机管理看企业文化建设 [J]. 吕梁教育 学院学报, 2012. 